\title{
FALÁCIAS E TEORIA DA ARGUMENTAÇÃO
}

"Não há coisa alguma que possa ter o nome de uma classificação dos modos como os homens chegam a um erro; e é muito duvidoso que possa haver alguma."

De Morgan ${ }^{1}$

David W. Silva Almeida

Graduando em Filosofia na Universidade de Brasília - UnB

\section{RESUMO}

Algumas abordagens formais e informais sobre o tema são aqui elencadas na tentativa de abrir um panorama no qual uma teoria da argumentação possa ser concebida, sendo esta um conjunto de modelos esquemáticos de raciocínio em que algumas normas são necessárias como forma de evitar as falácias. E, mais especificamente, o projeto de van Eemeren e Rob Grootendorst é aqui criticado via ataque à noção de validade lógica, que é tomada por eles sem nenhuma problematização, e serve de base às suas regras.

Palavras-chave: Argumentação; Falácias; Lógica; Pragmática; Correção

\begin{abstract}
Some formal and informal approach on the topic are here listed trying to give a domain in which a theory of argumentation can be elaborated, being this theory a model for reasoning in which rules are necessary as a way to avoid fallacies. More specifically, the project of Van Eemeren and Rob Grootendorst are here criticized, attacking the notion logical validity, which is accepted by them as given and serves as the basis for their ten rules.
\end{abstract}

Keywords: Argumentation; Fallacies; Logic; Pragmatic; Soundness

\section{Introdução}

O caminho percorrido nesse texto não retira o tema de uma para outra área, lógica formal ou informal, nem pretende, mas, trabalhando na interface entre as duas esferas de análise, propõe uma conexão de perspectivas que se somam mais coerentemente que as abordagens clássicas representadas por tratamentos semelhantes ao de Irving Copi em seu Introdução à Lógica. Objetiva-se mostrar que a certeza de que precisamos para assegurar apoditicamente a

\footnotetext{
${ }^{1}$ De Morgan, apud Copi, (1968, p. 73).
} 
correção (num sentido amplo: argumento aceitável e plausível) de um argumento não é encontrada seja na lógica formal, seja na lógica informal, mesmo admitindo maior rigor de critérios à lógica formal; que a fronteira entre elas não é tão nítida quanto frequentemente se imagina, e que mesmo perspectivas sólidas (que abordam aspectos caros à análise da argumentação real, e.g. posições prévias entre os envolvidos, relações de afinidade entre expositor e interlocutor, recursos emocionais para alcançar o assentimento do interlocutor) como a pragma-dialética precisam ser reformuladas em sua maneira de localizar as falácias e seus critérios para uma correta argumentação.

\section{As Falácias: entre a Lógica Formal e a Lógica Informal}

O papel central que ocupa a noção de falácia numa teoria da argumentação é compreendido no momento mesmo em que explicitamos em que consiste uma tal teoria. A lógica formal clássica consagrou a dedução como forma suprema de inferência. No entanto, sendo limitado o campo em que ela pode ser aplicada, a saber, somente aos argumentos formalizáveis, (em que não há elementos como emoção, temporalidade, causalidade, normatividade) ${ }^{2}$ houve uma crescente busca por analisar argumentos usados no cotidiano, largamente imbuídos dos vários "vícios da linguagem natural"3. Iniciaram-se, então, com os trabalhos de Asti Vera, Hamblin, Toulmin e outros, tentativas de estudar aqueles argumentos chamados informais, até então tematizados muito modestamente no Ocidente pela lógica. Constituiu-se por tais trabalhos o que hoje é comumente chamado de lógica informal. Uma teoria da argumentação pode ser encarada como a reunião das contribuições desse novo campo mais algumas noções - que não são absorvidas in globo - da lógica formal clássica. Procura-se elaborar meios seguros de julgamento dos argumentos, porém sem retirá-los de suas ocorrências particulares, isto é, seus contextos concretos, e de seus elementos problemáticos, como os citados acima: temporalidade,

\footnotetext{
${ }^{2}$ As lógicas temporais tematizam o tempo, assim como as lógicas deônticas o fazem com as normas, mas a lógica à qual me refiro é a proposicional clássica, o que não inclui as lógicas temporais, deônticas, da relevância ou qualquer outra lógica não-clássica, apesar de todas serem formais (não admito, para tanto, a inclusão de lógicas modais na L.P.C., mesmo que sejam extensões desta). Sei da dificuldade em assumir um conjunto de critérios como o mais adequado para se delimitar o que vem a ser formalização, e não defendo algum conjunto de regras que o façam, apenas assumo e critico os critérios vigentes por reconhecer graves insuficiências neles. Não é objetivo deste trabalho propor critérios para a formalização. Meu tema é outro.

${ }^{3}$ Diz-se que sistemas de lógica formal permitem fazer análises de argumentos informais. A lógica clássica, e.g., permite-o e efetivamente é utilizada por alguns autores para se reconstituir argumentos que aparecem no cotidiano. Porém, não é qualquer argumento informal que a L.P.C. (lógica proposicional clássica) pode incluir em seu escopo de estudo. Apesar de termos atualmente formalizações de termos como "diversos", esta formalização não se dá no âmbito da L.P.C. Os quantificadores modulados de Walter Carnielli estão fora dela.
} 
normatividade, causalidade, relevância. As diretivas construídas em tal sentido delimitarão o espaço reservado aos argumentos corretos, e, por conseguinte, aos argumentos falaciosos, fora desse campo.

Segundo Irving Copi, uma falácia é uma forma de raciocínio incorreto que se reveste de um teor persuasivo tal que lhe é conferida aparente correção (COPI, 1968, p. 73). Assim, falaciosos seriam os argumentos que, apesar de, à primeira vista, mostrarem-se corretos, com uma análise mais detalhada seriam "desmascarados". De pronto salta aos olhos os problemas abertos por essa caracterização. Em primeiro lugar, a noção de correção não é explicitada pelo autor. Ele a entende mais ou menos como uma configuração argumentativa de qualidade suficiente para que um ouvinte atento assinta ao argumento. Certamente um entendimento que envolva tantos elementos psicológicos não tematizados na explicação da correção não pode ser tomado numa abordagem lógica, mesmo que informal, da argumentação, porque estes influenciam implicitamente a correção. Além disso, Copi toma como pressuposta a noção de raciocínio incorreto. Sendo as falácias um subconjunto dos argumentos incorretos (por motivos explicados na seção 4), é mister portanto esclarecer em que consiste a incorreção. Outro problema sobre o qual o autor não se atém é a relativização com que tem de lidar com o tema se aceita a existência de falácia apenas quando condicionada a um juízo individual. Se um argumento é falacioso por causar engano em alguém, mesmo atento, pode ser que outra pessoa mais rigorosa não "caia no mesmo erro". Essa caracterização de falácia não nos é suficiente porque incorre no subjetivismo.

Walton apresenta um quadro melhor das falácias. Para ele não há argumentos falaciosos em si mesmos, mas usos falaciosos de argumentos que podem ser corretos em vários contextos. Em seu livro The Place of Emotion in Argument, o autor reivindica a legitimidade das falácias de emoção em determinados contextos específicos de argumentação, abrangendo entre elas os argumentos ad populum (apelo ao povo ou ao sentimento popular para apoiar uma conclusão), ad misericordiam (recurso à piedade como meio de comover e facilitar a concordância), ad baculum (recurso a uma ameaça, força ou medo para forçar a aceitação) e ad hominem (ataque à pessoa com quem se discute, desviando-se do tema da questão), que são por ele defendidos em inúmeros contextos concretos, os quais não preciso aqui mencionar. A importância do trabalho de Walton repousa não no fato de que sua concepção de falácia é primordialmente contextual - tese já presente em Van Eemeren - abrindo espaço para que qualquer argumento possa se tornar correto ou falacioso analisando- se os casos em que ocorrem, mas por incorporar um âmbito de argumentos - os argumentos de emoção - em grande medida 
desprezados pela tradição (os estoicos foram uma exceção porque admitiam a retórica como parte da lógica). Estes quase sempre foram tomados como uma forma corrompida de argumento que precisava ser depurada de seus elementos afetivos para que se pudesse iniciar uma análise. Porém, Walton entende que as emoções não podem ser extirpadas como uma parte destacável de um corpo, porque elas são indissociáveis dos argumentos em que ocorrem. Alguém poderia objetar dizendo que, se aceitamos o dito acima, temos de reconhecer que mesmo uma frase aritmética pode ser expressa imiscuída de emoção, e que, portanto, todo e qualquer argumento é passível de ser emocionalizado. Porém, o que pretendo dizer com "argumentos em que ocorrem" é precisamente os quatro tipos de argumentos acima reconhecidos pela tradição como emocionais, apesar de admitir que várias outras formas de argumentos em seus usos frequentemente tidos como isentos de afetos comportam sim, num grau menor, elementos afetivos. Assim como não há argumentos falaciosos per si também não há argumentos nãoemocionais universais, mas ocorrências em que são tomados dessa maneira.

É sabido que tradicionalmente as falácias são tratadas de modo "aproximadamente" informal na literatura especializada, mesmo sempre fazendo parte de análises formais nos livros de lógica. Geralmente, reserva-se a elas não mais que um capítulo, que serve de apêndice ao corpo majoritário de teses lógico-formais. Procede-se à divisão confusa e problemática entre falácias formais e não-formais. Isto porque às primeiras pertencem aqueles argumentos inválidos devido inadequações de sua forma, que, se comparada à forma dos logicamente válidos, apresenta variação, entretanto não se sabe concludentemente por que motivo a forma dos logicamente válidos é tal que devem ser assim encarados. Susan Haack problematizando a questão reconhece haver similaridades estruturais entre argumentos informais (HAACK, 2002, p. 52). Estas semelhanças são reveladas pela relevância semântica que algumas expressões como “e”, “ou”, “não", “todo", "se... então", “existe” apresentam na linguagem natural. A importância destes termos possibilitaria a construção de uma linguagem artificial que usa apenas eles na elaboração de uma gramática ${ }^{4}$. Assim, quaisquer que sejam as palavras ocorrentes numa proposição em linguagem informal, sua validade forçosamente será derivada da posição que ocupam tais termos "semanticamente privilegiados" e, somente deles, em linguagem formal. Haack sintetiza da seguinte forma a questão:

\footnotetext{
${ }^{4}$ Estes termos formalizados num sistema lógico correspondem às constantes proposicionais - operadores lógicos - formadas pelos conectivos e quantificadores, no entanto, a rigor, um sistema lógico precisa, além destes, de variáveis de objeto, constantes de objeto, letras predicativas e da constante de predicado "=", mais os símbolos auxiliares '(', ')'. Cf. Gomes (2012, p. 01).
} 


\begin{abstract}
Os sistemas lógicos formais visam formalizar os argumentos informais, para representá-los em termos precisos, rigorosos e generalizáveis. E um sistema lógico formal aceitável deve ser tal que, se um argumento informal dado é nele representado por um certo argumento formal, então esse argumento formal deveria ser válido no sistema apenas no caso de ser válido o argumento informal no sentido extrassistemático (HAACK, 2002, p. 42).
\end{abstract}

No entanto, essa não é a única maneira de resolver a questão. Uma alternativa consiste em renunciar juízos pré-formais de validade para alcançar um nível razoável de simplicidade na teoria formal. Outra solução é alterar a teoria formal para que ela comporte avaliações de argumentos informais, ou ainda reavaliar a noção de representação formal de argumentos informais utilizada na tentativa de construir uma outra maneira de representação. Dizer que "se eu acordei, então eu estava dormindo; eu acordei, portanto, eu estava dormindo" (Modus Ponens) não garante a validade da forma: " $\mathrm{P} \rightarrow \mathrm{Q}, \mathrm{P} \therefore \mathrm{Q}$ ". Ela deve ser explicada e legitimada via confrontação com os exemplos concretos, e esta confrontação tem mostrado a inadequação desta forma em inúmeras ocorrências particulares (exemplos na seção 4). Entendo a lógica como um tipo de especulação abstrata, mas derivada da experiência em última instância. Assim, a atribuição de validade a uma forma argumentativa depende de uma averiguação empírica para cada uma em questão. Se a lógica pretende abstrair dos casos particulares e construir generalizações que valham para todo e qualquer caso, esta forma de argumento não corresponde a esse objetivo, já que é invalidada em algumas instanciações, o que é mais do que suficiente para desabilitar a forma do argumento, de vez que uma apenas já o faria. Para tanto, o modelo formal válido precisa ser reformulado ou fundado em outras bases que não a ultrageneralidade e neutralidade tópica - problematizadas na seção 4 - e, só então uma distinção formal informal pareceria menos arbitrária.

As falácias não-formais correspondem aos argumentos reais incorretos e não passíveis de formalização (ao menos até presentemente). Esta insuficiente e vacilante exposição das falácias pelos autores lógicos tradicionais reflete-se na indecisão sobre como tratá-las. Se formalmente tratadas, uma teoria lógica das falácias se faria necessária, onde o método formal de análise de argumentos utiliza-se do modelo dedutivo na elaboração da forma de inferência válida. Aqui, o expediente que prescreve a validade e, portanto, aceitabilidade dos argumentos, é sua correspondência a uma série de regras que os organizam segundo a forma em que ocorrem distribuindo-os em válidos e inválidos. O estudo tradicional das falácias não se situa aqui. E, se fossem tratadas informalmente, as falácias ocupariam um tópico dentro da invalidez, pois cada falácia é um caso particular de argumento inválido, segundo os critérios clássicos (COPI, 
1968, p. 73-88) - tema que fica à margem da lógica formal e é trabalhado em esquemas argumentativos, onde a validez não está restringida apenas à inferência dedutiva, mas também leva em conta a abdução, indução, inferência lexical, dentre outras formas de inferência. Dizer que os esquemas argumentativos estudam a invalidez é afirmar que, deixando à lógica formal o estudo exclusivo dos argumentos válidos, tais estruturas buscam também dentro do grande conjunto de argumentos inválidos aqueles que, a despeito disso, conservam grau de correção (num sentido amplo) suficiente para figurarem legitimamente em quaisquer argumentos reais (argumentos que usam a linguagem natural). O que também não é o caso, isto é, o método de análise das falácias não é estritamente informal.

Também os conteúdos dos argumentos são trabalhados diferentemente nos dois casos. A matriz formal despreza primariamente qualquer consideração sobre os conteúdos dos argumentos para a efetivação da análise. Abstrai-se, em grande medida, dos conteúdos concentrando-se preponderantemente na disposição locacional das sentenças e nas relações constantes entre premissas e conclusão. Já a lógica informal entende haver necessidade de levar-se em conta equitativamente aspectos sintáticos e semânticos. Um aspecto não deve se sobressair ao outro discrepantemente.

O que chamamos de lógica informal aqui é conhecido também, e mais frequentemente, como pragmática lógica, por se ocupar do uso que um argumentador faz de sentenças numa situação dialógica que envolve perguntas e respostas. Aqui, os argumentos formais são não apenas insuficientes por reduzirem-se a um conjunto de questões muito restrito se comparado ao universo de problemas aos quais somos cotidianamente expostos, mas também inadequados (em algumas situações abaixo examinadas). A preocupação exclusivamente sintático-semântica é deixada à lógica formal ${ }^{5}$. Porém, na análise informal, o significado de cada sentença não é deixado de lado; a ênfase recai sobre a pragmática, por se tratar de um método que visa estudar esquemas estruturais presentes nas argumentações reais em que muitas outras formas de inferência são usadas legitimamente além da dedução.

\section{Uma Primeira Aproximação à Abordagem Pragma-dialética da Argumentação}

A teoria pragma-dialética da argumentação, desenvolvida por autores como Asti Vera, Hamblin, Van Eemeren, Toulmin, consiste na análise preponderantemente pragmática dos

\footnotetext{
${ }^{5}$ Cf. Walton (2012, Capítulo 01).
} 
argumentos dentro de contextos dialogais, portanto empíricos, em que dois ou mais arguidores interagem numa discussão na qual perguntas e respostas assumem um papel determinante. Não há abstração das características concretas dos argumentos. Arguidor, plateia, tema, objetivo da discussão, o contexto ético no qual cada discurso é proferido, são alguns dos elementos não deixados de fora dessa abordagem. Van Eemeren e Rob Grootendorst definem a argumentação como segue:

A argumentação é uma atividade verbal, social e racional que objetiva convencer um crítico razoável da aceitabilidade de um ponto de vista apresentando um conjunto de uma ou mais proposições para justificar este ponto de vista (EEMEREN, 2006, p. 381)

O objetivo perseguido é a resolução de desacordos, que são expostos no estágio de abertura, onde também se delimita o problema, e cada parte apresenta seu ponto de vista sobre o tema. O segundo estágio, diferença de opinião, consiste no momento em que os arguidores expõem suas teses conflitantes. Segue a este o estágio de argumentação, no qual os arguidores propriamente confrontam um ao outro. Aqui se concentra os maiores esforços de cada parte em tentar convencer o oponente. Finalmente se chega ao estágio conclusivo ou de resolução em que um dos arguidores deve conceder razão à outra parte por reconhecimento de que seus argumentos eram insuficientes para defender sua antiga posição, modificada após o debate ${ }^{7}$.

A quadripartição do momento argumentativo poderia se prestar melhor a seus objetivos caso oferecesse maiores especificações. Não há como delimitar com clareza onde inicia a argumentação, ou se ela já não é requerida mesmo no primeiro estágio. Também é difícil definir quando se chegou ao fim da discussão para que o último estágio se instaure, nem tampouco é razoável acreditar que as pessoas terão a honestidade de reconhecer, finda a discussão, que estavam equivocadas. Não é isso que presenciamos nas discussões cotidianas em que experienciamos sempre as indisposições em admitir um erro no próprio raciocínio. Há uma espécie de visão benevolente dos autores em pressupor um tipo de humano capaz de renunciar seus anseios de vaidade em benefício de uma discussão pretensamente objetiva. Apesar de admitirmos que suas propostas partem de uma situação ideal de argumentação, não é, porém razoável, construir uma teoria alheia às limitações inerentes ao ser humano. Ela precisa ser realista no sentido de considerar nossos pendores mais diretamente relacionados à prática

\footnotetext{
${ }^{6}$ Tradução minha do trecho: La argumentación es uma actividad verbal, social y racional que apunta a convencer a um crítico razonable de la aceptabilidad de um punto de vista adelantando uma constelación de uma o más proposiciones para justificar este punto de vista. (Cf. A. VERA, 2010, p 152).

${ }^{7}$ Cf. Walton (2012, Capítulo 01).
} 
argumentativa, de forma que as normas exijam dos arguidores posições ético-lógicas com razoável grau de sensatez.

No entanto, essa abordagem possui enormes avanços em relação ao tratamento padrão das falácias. Falhas como a enunciação ad hoc das justificativas para a classificação de uma falácia (alguns autores apresentavam motivos bastante implausíveis para seu modelo de divisão dos tipos de falácia), a assistematicidade com que eram agrupadas e tematizadas, o teor moralista e exageradamente preventivo contra os argumentos falaciosos, e sua análise desconectada do contexto no qual aparece em benefício de uma ultra-generalidade, foram todas superadas, apesar de conservar ainda dificuldades inquietantes para a elaboração de uma teoria da argumentação.

Julio Cabrera apresenta um método alternativo de seis passos para a avaliação dos $\operatorname{argumentos}^{8}$ que serve adequadamente como propedêutica às dez regras de Van Eemeren e Rob Grootendorst (listadas na seção 3):

1. Existência de argumento. Há que se ver se o pronunciamento se trata mesmo de um argumento, ou se o arguidor está apenas descrevendo uma situação ou fazendo perguntas;

2. Reconstrução do argumento. Aqui se verifica qual é o argumento, se é apenas um e se há vários subargumentos implícitos no argumento maior. Delimita-se as premissas e a conclusão. Algumas vezes esse passo exige a reorganização da ordem em que os argumentos apareceram, para que sejam visualizáveis num padrão esquemático que facilite a análise. Também é possível elaborar gráficos que sintetizem e melhorem a visualização do argumento;

3. Clareza dos termos e valor de verdade das premissas. As palavras usadas precisam ser claras aos dois arguidores, se houver termos não compreendidos, há que se esclarecê-los. É plenamente provável que não haja consenso acerca dos conceitos em questão. Deve-se questionar também se as premissas - as quais podem ser implícitas - são verdadeiras ou aceitáveis, e, ainda, se são mais fortes que a conclusão ${ }^{9}$, o que as tornaria inadequadas;

4. Correção do argumento. Procura-se saber aqui se as conclusões derivam

\footnotetext{
${ }^{8} \mathrm{O}$ método em questão é uma síntese de vários autores (Fischer, Fogelin/Amstrong, Kahane, Copi, etc) feita por Julio Cabrera conforme notas de aula de março de 2007 do estudante Marco Antônio L. Abreu).

${ }^{9}$ Uma premissa é mais forte que sua conclusão quando exige comprometimento com uma tese mais difícil de defender que a tese da conclusão, e.g. "Se Deus existe, então eu existo. Deus existe. Portanto, eu existo".
} 
das premissas, se o argumento é cogente, convincente, contundente. Avalia- se a plausibilidade do argumento. Esse critério vai além do requerido na dedução, porque admite a possibilidade de existir um argumento dedutivo não convincente;

5. Propósito do argumento. Passo em que a intenção do arguidor é averiguada, podendo ser de explicação, prova, refutação, causar polêmica, escandalizar, confundir, confortar, educar, etc. E ainda se ela é atingida;

6. Fonte e alvo do argumento. Relacionado ao anterior, esse último passo pretende saber se a origem do argumento é, por assim dizer, "autorizada", sabendo que mesmo um ótimo argumento pode ser rejeitado se o arguidor pertence a um grupo fortemente desprezado pela plateia, ou não é habilitado para o tema. Ou ainda se a arguição despertar receios, ou for introduzida de modo agressivo para o público.

\section{Problemas em aberto no projeto pragma-dialético de Frans van Eemeren e Rob Grootendorst}

Frans van Eemeren e Rob Grootendorst (EEMEREN, 1995, p. 135) propõem uma lista de dez regras com as quais pretendem dar conta dos requisitos a serem observados numa discussão ideal. Uma análise geral do texto mostra que, além de ser arbitrário o número de regras, que, aliás, poderia muito bem ser acrescido com diversas outras, estas individualmente apresentam várias dificuldades.

O autor, fortemente influenciado por Hamblin (HAMBLIN, 1970), reconhece que o tratamento padrão das falácias sofre de graves falhas teóricas e práticas. Em sua proposta, assume primeiramente que toda falácia é um erro lógico, movimento equivocado no discurso argumentativo, e que se constitui num obstáculo ou impedimento para a resolução de uma divergência. Propõe uma abrangente teoria da argumentação que abarque todo o domínio das falácias. Para isto, concebe dez regras (EEMEREN, 1995, p. 135-136) ${ }^{10}$, as quais transcrevo e comento abaixo:

Regra 01. As partes não devem impedir-se umas às outras de apresentar pontos de vista ou pô-los em dúvida.

Deve haver irrestrita liberdade para os arguidores proporem e criticarem pontos de vista. Uma forma de quebrar a regra é praticada se uma das partes coloca limites no

\footnotetext{
${ }^{10}$ Eemeren, Frans van e Grootendorst, Rob. The Pragma-Dialectical Approach to Fallacies, 1995. Trad. minha. Disponível no site: www.ditext.com/eemeren/pd.html.
} 
que a outra quer expressar. Argumentos ad baculum violam claramente essa regra, se usados para amedrontar o oponente e fazê-lo desistir de defender um ponto que a outra parte não quer tematizar.

Regra 02. Uma parte que apresenta um ponto de vista está obrigada a defende-lo se a outra lhe solicitar.

Não apenas quando solicitada, pois o ônus da prova é de quem defende um ponto de vista do ouvinte. Uma maneira clássica de violar essa regra é conhecida como falácia da inversão do ônus da prova, praticada quando o apresentador de uma tese exige que seu oponente prove o contrário, sendo dele essa responsabilidade. Já ouvimos algumas vezes o dito: "Prove você primeiro que isso não é assim."

Regra 03. O ataque de uma parte contra um ponto de vista deve referir-se ao ponto de vista que realmente foi apresentado pela outra parte.

Se o ponto de vista questionado não for o que anteriormente foi defendido pela outra parte essa regra é violada. A falácia do espantalho é a que melhor representa a violação da regra por corresponder aos momentos em que uma parte distorce, acresce, diminui ou desvia o ponto para dizer que essa forma de argumento esdrúxula (que ele criou) foi a defendida pelo oponente.

Regra 04. Uma parte só pode defender seu ponto de vista apresentando uma argumentação que esteja relacionada com esse ponto de vista.

Aqui há a exigência por usar argumentos relevantes, que se refiram diretamente ao tema tratado. Mas, mesmo que se use argumentos relevantes eles precisam estar em consonância com o que está sendo tratado. A falácia da conclusão impertinente ou ignoratio elenchi é usada na violação dessa regra.

Regra 05. Uma parte não pode apresentar algo falsamente como se fosse uma premissa deixada implícita pela outra parte, nem pode negar uma premissa que ela mesma deixou implícita.

É levada em conta a possibilidade bastante real de premissas implícitas. Como na regra 4, essa é violada quando "se colocam palavras na boca do outro" (VERA, 2008, p. 178). 
Regra 06. Nenhuma parte pode apresentar falsamente uma premissa como se fosse um ponto de partida aceito, nem pode negar uma premissa que representa um ponto de partida aceito.

Se não há compromisso com as premissas de partida, não é proveitosa a discussão. Tanto a defesa como o ataque pressupõem a aceitação de um conjunto comum de premissas. Um recurso que fere a regra consiste no uso da falácia da pergunta complexa. Entre dois assaltantes que prometeram um ao outro não mais roubar, poderia surgir dias depois a pergunta capciosa:

“Quanto você roubou?”, onde está implícita a afirmação: "Você roubou!”.

Regra 07. Uma parte não pode considerar que um ponto de vista foi defendido conclusivamente se a defesa não foi levada a cabo por meio de um esquema argumentativo apropriado que foi aplicado corretamente.

As noções de conclusividade e esquema argumentativo apropriado são por demais vagas, porém a intenção de Van Eemeren é captada quando se considera que o argumentum ad populum ou de apelação à maioria é o tipo de falácia que ela pretende evitar (VERA, 2008, p 175).

Regra 08. Em sua argumentação, uma parte só pode usar argumentos que são logicamente válidos ou capazes de serem validados por fazerem explícitas uma ou mais premissas implícitas.

Esta é a regra à qual dedicaremos maiores considerações. A intenção perseguida por Van Eemeren na exigência de validez lógica a todo argumento usado na discussão parece, à primeira vista, legítimo e justificado. Ele pretende blindar a discussão das falácias formais (lembrar da crítica feita na página 4 à divisão entre falácias formais/informais): afirmação do consequente, negação do antecedente, falácia de composição, falácia de divisão). No entanto, o autor se vê em difíceis problemas, que serão expostos ao final da lista de regras.

Regra 09. Uma defesa fracassada de um ponto de vista deve ter como resultado que a parte que o apresentou se retrate dele, e uma defesa conclusiva deve ter como resultado que a outra parte se retrate de suas dúvidas acerca do ponto de vista. 
A regra mais pragmática de todas é, concomitantemente, a mais ingênua. Há uma falácia conhecida pela longa expressão falácia de rejeição de retratação de um ponto de vista que não foi defendido exitosamente, que é cometida pela parte que "perdeu a argumentação". No caso oposto a falácia de rejeitar a retratação da crítica do ponto de vista que foi exitosamente defendido, é praticada quando o "perdedor" na discussão não se retrata de seu ponto.

Regra 10. As partes não devem usar formulações que resultem insuficientemente claras ou confusamente ambíguas, e devem interpretar as formulações da parte contrária tão cuidadosa e exatamente como lhes seja possível.

A última regra poderia ser a primeira e também é uma espécie de meta-regra. Pode ser violada por vários tipos de falácia, de vez que é geral, mas a anfibologia, argumentar a partir de proposições cuja formulação é ambígua devido sua estrutura gramatical, é uma em especial usada para violá-la.

Como se vê, estas regras versam sobre uma gama de temas, desde o assunto da arguição, a pertinência dos argumentos, os implícitos, a passagem inferencial, os participantes até a linguagem (clareza dos termos). Duas delas - as únicas que tratam da passagem inferencial na lógica formal - deixam especialmente fragilizado o projeto. A regra 07, segundo Carlos Asti Vera (VERA, 2008, p. 175-176), é uma espécie de meta-regra sob a qual todas as outras seriam sub-regras porque estabelece um padrão geral ao qual todas as outras se submetem. Todas as outras regras também poderiam incluir em sua formulação o texto desta regra que ainda continuariam sendo as mesmas regras. Da mesma forma, a regra 08, reservando à argumentação o critério lógico da validez, estende sua aplicação a todas demais.

Porém, esse é o menor problema com a regra 08, porque ela lança fora da argumentação correta todo e qualquer argumento inválido. Mas, para a apreciação deste tópico, um esclarecimento prévio é necessário.

Para um lógico formal clássico não há qualquer dificuldade em desprezar a invalidez. Isto porque toda sua atenção se concentra única e exclusivamente nas estruturas de argumentos válidos, aqueles fora dessa categoria permanecem alheios à sua atenção. Entretanto, alguns autores contemporâneos (e.g. Cabrera, Walton) têm reconhecido a legitimidade de tipos de argumentos que, apesar de serem inválidos, conservam suficiente correção para serem usados plausível, acertada e coerentemente numa argumentação séria. Outrossim, admite-se que um 
arguidor utiliza argumentos reais, os quais inescapavelmente estão imbuídos de expectativas, crenças, temores e intenções. Estes argumentos são por ele aceitos não apenas por sua validez, mas também por serem convincentes, relevantes e auxiliarem-no a sustentar suas intuições mais primordiais. Fatores psicológicos fazem parte de um esquema argumentativo, não só critérios lógicos, que podem algumas vezes ser inadequados, como o mostra Cabrera, que, numa crítica a dois possíveis dogmas da lógica formal clássica - ultrageneralidade e neutralidade tópica -, fez duas distinções relacionando validez lógica e correção de um modo que amplia a maneira de análise dos argumentos corretos e cria instrumentos com os quais se pode renunciar o dogmatismo com que são tratados alguns conceitos centrais da lógica formal. Certamente por influência de sua aplicabilidade generalizada em várias áreas de conhecimento, e uso de seus termos na matemática, especialmente, como apontou Quine em seu "Dois Dogmas" (QUINE, 1951, p. 20-43).

Porém, se poderia argumentar que a lógica informal é por demais incerta e, tendo argumentos canceláveis, não pode revogar o título de análise lógica, já que seus argumentos estão abertos à refutação, revisão e revogação. Certamente que uma conclusão de um argumento informal não é definitiva, e mesmo que o argumento seja cogente, ele não assegura necessariamente a conclusividade da conclusão. Isto se deve ao caráter mesmo da argumentação informal, que não se utiliza exclusivamente da inferência dedutiva, como foi dito. Porém, tal fato não rebaixa o valor da lógica informal. A espécie de questões com as quais ela lida envolve um tipo diferenciado de variáveis, que não comportam satisfatoriamente uma análise puramente formal, requerem uma abertura a relações mais amplas que as formalizáveis.

\section{Argumentos Infra-válidos e Supra-válidos}

A fragilidade dos conceitos lógico-formais de validez e correção, e também a insatisfatoriedade do projeto de van Eemeren e Rob Grootendorst são expostas com o auxílio dos conceitos de infra-validade e supra-validade formulados por Cabrera como crítica à lógica formal. Isto porque o projeto pragma-dialético deles peca no pressuposto mais primordial de assumir que a noção de validez lógica é suficientemente rigorosa para excluir todos os argumentos problemáticos, e, ao mesmo tempo, abranger todos aqueles aos quais não se pode questionar a correção. Suas dez regras para uma argumentação crítica presumem que o terreno fundante da discussão é assegurado pela lógica formal através da validade, critério central 


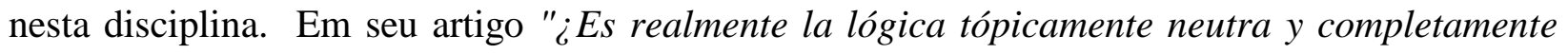
general?", Cabrera diz que a lógica clássica agrupa os argumentos em dois grandes grupos: segundo a validez e segundo a correção. A validez-L (validez lógica em terminologia carnapiana) é tradicionalmente definida, de maneira um tanto vaga, como um modo de inferência que garante a passagem das premissas para a conclusão sem auxílio de nenhum outro pensamento fora daquele expresso pelas premissas, e que conserva confiavelmente a necessidade da passagem com elevado grau de certeza. A correção é o simples acréscimo da condição de veracidade às premissas de um argumento válido-L. Isto é, será correto o argumento que é válido e possui premissas verdadeiras. No entanto, Cabrera reconhece haver um tipo de exigência mais rigorosa e intuitivamente respaldada que a validez ou mesmo a correção para que se dê assentimento a um argumento formal e informal, a correção- $A$, por ele entendida (mas não definida) como a propriedade de uma conclusão derivar das premissas de modo a respeitar intuições básicas. E a partir daí, defende a fragilidade da noção de validez-L frente à incorreção-A. Raciocínios válidos-L e corretos podem não possuir conclusões que se seguem de suas premissas, ou seja, podem ser incorretos-A, como no caso abaixo, que exemplifica uma instanciação da comutatividade da conjunção ( $\mathrm{X} \square \mathrm{Y} \therefore \mathrm{Y} \square \mathrm{X}$ ):

\section{(Exemplo I)}

Premissa (A): Joaquim Barbosa votou e saiu do tribunal.

Conclusão(B): Joaquim Barbosa saiu do tribunal e votou.

A premissa (A) fala de uma situação em que duas ações são executadas em momentos diferentes. Há uma sucessão temporal entre uma e outra, de modo que a conclusão deveria respeitar a ordem em que as ações aparecem, mas não o faz. Na sentença (B) temos uma nova ordenação dos fatos, o que modifica o sentido de (A), dando a entender que Joaquim Barbosa votou num lugar que não o tribunal. Estes são os raciocínios infra-válidos. Assim, a validez não garante a correção- $A$.

Contrariamente, procura mostrar que argumentos determinados como inválidos ou mesmo falaciosos "podem admitir infinitas instâncias sistematicamente corretas-A" (CABRERA, 2003, p 20). Estes Cabrera os denomina supra-válidos. Examinemos o caso clássico da falácia formal da negação do antecedente $(\mathrm{X} \rightarrow \mathrm{Y}, \sim \mathrm{X}, \therefore \sim \mathrm{Y})$ :

\section{(Exemplo II)}

Premissa (A): Se Vicente Ferreira vive, então virá à Brasília. 
Premissa(B): Vicente Ferreira não vive.

Conclusão(C): Portanto, Vicente Ferreira não virá à Brasília.

Apesar de se admitir que Vicente Ferreira poderia não vir a Brasília por outros motivos não mencionados nas premissas, é de se esperar que esse recurso não seja acionado por ser claramente impertinente. Pois, quando argumentamos, esperamos que os motivos para a conclusão sejam todos retirados das premissas mencionadas. E, intuitivamente temos total adesão à conclusão admitindo as premissas listadas. Assim, apesar de inválido, o raciocínio é correto-A.

A restrição de van Eemeren ao uso apenas de argumentos válidos dentro das discussões veta completamente a possibilidade de que outros, denominados supra-válidos, façam parte do elenco de teses. Isso pode inviabilizar o sucesso da argumentação, já que somente um conjunto minúsculo de argumentos é aceito para entrar no jogo e toda uma gama de teses corretas-A deixada de lado. A argumentação não pode abstrair dos inúmeros tipos de argumentos reais possíveis e eleger um campo tão reduzido de possibilidades argumentativas.

A crítica de Cabrera estende-se não apenas aos dois conceitos relatados. No mesmo artigo, ele tenta defender a tese de que a ultra-generalidade lógica é incompatível com a aplicabilidade universal, conceitos abraçados pela tradição como firmemente fundamentados através do método de contra-exemplos, chegando à conclusão de que a lógica não estuda o suposto "objeto qualquer", mas espécies muito particulares de objetos. Os exemplos I e II mostram que objetos atingidos pela temporalidade e causalidade não são tomados pela lógica formal, já que sua análise se retira de tais tipos de objetos. Assim, objetos não-temporais e não-causais é que são estudados por ela, e não o pretenso objeto qualquer. Defendendo-se a neutralidade tópica, é forçoso admitir que a lógica formal não possui a aplicação geral a qualquer objeto. E endossando-se a tese de ultrageneralidade, incorre-se, fatalmente também, na restrição a temas específicos, isto porque uma tese se opõe à outra, excluindo-se mutuamente. Não é possível à lógica ser geral e observar, concomitantemente, o contexto. Portanto, tentando salvar a neutralidade temática, a lógica formal incorre na perda de adequação, sensibilidade temática; e, se aceita ser sensível ao tema, renuncia à ultra- generalidade. Assim, as duas características fulcrais da lógica moderna (as quais colocam em jogo também as noções de validade e correção lógica), parecem não suportarem-se num mesmo sistema lógico.

\section{Conclusão}


Do dito percebe-se a dificuldade e os limites em elaborar uma teoria argumentativa que componha-se de contribuições advindas da lógica formal e informal. Apesar de admitirmos um grau elevado de rigor aos argumentos formais, é patente a inadequação destes em várias situações de uso. Por outro lado, os argumentos informais possuem características suficientes para fazerem parte do elenco de teses numa argumentação real. As críticas feitas aqui pretenderam criar um panorama em que se possa conceber argumentos cogentes na interface formal/informal e incorporar ferramentas argumentativas das duas abordagens em conjunto. $\mathrm{O}$ tema foi apenas ventilado, não se pretendeu exauri-lo por ter-se consciência de sua amplitude e complexidade. Porém, a via de análise aberta mostrou que a investigação formal da argumentação já não corresponde aos anseios impostos pelos problemas atuais por se abster a um campo limitado de questões que deixam variáveis relevantes, como a motivação de um arguidor, de fora. Já a investigação informal, apesar de declinar da pretensão de certeza matemática das conclusões, possibilita um tratamento razoável da argumentação real, e de como ocorrem os argumentos e seus desvios, as falácias, no cotidiano. Estas, mais que construções impróprias de estruturas de argumentos corretas, são também usos inadequados de instâncias argumentativas, que podem aparecer como corretas num outro contexto apropriado como apresentado neste texto segundo Walton. Aqui, a abordagem pragmática e dialética da argumentação se revela privilegiada para o trato destas questões por ser sensível à dinâmica discursiva e às ocorrências singulares que marcam a particularidade de cada argumento, assim considerado como um caso específico de comunicação, e não, como estrutura rígida que se repete sempre que usado por qualquer arguidor.

\section{Referências Bibliográficas}

ALCHOURRÓN, Carlos. Lógica. Madrid: Editorial Trotta, 1995.

CABRERA, Julio. ¿Es realmente la lógica tópicamente neutra y completamente general? Ergo, Revista de Filosofía, México, No 12, 2003. p. 7-33.

.Contra La Condenación Universal de los Argumentos Ad Hominem. Revista Internacional de Filosofia, Centro de Lógica, Epistemologia e História da Ciência-Unicamp, v. XV n.01, 1992. p. 74-92. Abril.

COPI, Irving. Introdução à Lógica. São Paulo: Ed. Mestre Jou, 1968.

EEMEREN, Frans H. van, \& Houtlosser, P. Argumentative Indicators - A Pragma-dialetical 
Study. Amsterdã. Ed. Springer, 2006.

EEMEREN, Frans H. van \& Rob Grootendorst. The Pragma-Dialectical Approach to Fallacies. Fallacies: Classical and Contemporary Readings, Pennsylvania University Press, Volume único,1995. P. 130-144.

GOMES, Nelson. Linguagens Extensionais e Intensionais: curso de Filosofia Analítica. $1^{\circ}$ Semestre de 2012. UnB. 14 f. Notas de Aula. Impresso.

HAACK, Susan. Filosofia das Lógicas. Trad. Cezar Augusto Mortari e Luiz Henrique de Araújo Dutra. São Paulo: Ed. Unesp, 2002.

HAMBLIN, Charles Leonard. Fallacies. Londres: Ed. Methuen e CO LTD, 1970.

QUINE, W. van O. Two Dogmas of Empiricism. The Philosophical Review, Harvard University Press, v. 60, 1951. P. 20-43.

TOULMIN, Stephen Edelston. The Uses of Argument. University of Southern California: Hardback, 1958.

VERA, Carlos Asti. Escenarios Argumentativos: Iniciaciación a La Evaluación de Argumentos. Buenos Aires: Ed. Educando, 2008.

WALTON, Douglas N. Lógica Informal: Manual de Argumentação Crítica. Trad.: Ana Lúcia R. Franco e Carlos A. L. Salum. $2^{\text {a }}$ Ed. São Paulo: Editora WMF Martins Fontes, 2012.

The Place of Emotion in Argument. Pennsylvania: The Pennsylvania State University Press, 1992. 